\title{
Assessment of Landscape Function as an Information Source for Mine Closure
}

\author{
D.J. Tongway School of Resources, Environment and Society, Australian National University, Australia
}

\author{
J.A. Ludwig CSIRO Sustainable Ecosystems, Australia
}

\section{$1 \quad$ INTRODUCTION}

A pressing need in mine closure is for a "toolbox" of procedures that can provide evidence that agreed completion criteria have been met. We propose that one of those tools be based on the assessment of landscape function, which we define as how well a landscape performs as a biophysical system. A functional landscape retains vital resources against erosion, whereas a dysfunctional landscape tends to leak them beyond the landscape boundaries. This tool is based on published principles in landscape ecology, is quickly learnt, can be used without modification in a range of biomes and provides information about ecosystem trend over time, comparing rehabilitating sites with reference sites to examine the rate of rehabilitation progress. The procedure uses quickly assessable indictors of the status of biotic and abiotic processes acquired on gradsects, a highly efficient data acquisition system. Interpretation of rehabilitation progress in terms of resilience, self-sustainability and stability are design features.

\section{BACKGROUND}

Over the last decade and a half, there has been increasing interest in issues surrounding mine closure, both in Australia (ANZMEC, 2000, Environment Australia, 2002) and globally (UNDP, 2005). This interest has been in response to increasing public pressure for lands where mining has ceased, to be rehabilitated to agreed success criteria. Rehabilitation in this context has been defined as "the return of disturbed land to a stable, productive and self-sustaining condition, after taking into account beneficial uses of the site and surrounding land"; completion criteria are defined as "an agreed standard or level of performance which demonstrates successful closure of a site" (ANZMEC, 2000). This matter of an "agreed standard" remains a subject of some debate and uncertainty among all the stakeholders, and the various statements of objectives generated, whilst having broad similarity, are often couched in terms so value-laden or conceptually complex that direct monitoring by straight-forward procedures is not possible.

A monitoring procedure able to supply information to many of these issues would be of undoubted value to the Mining, the Regulatory and the Consulting industries as a group. The procedure described here is well founded in classical science with demonstrated statistical relationships between assessed indices of landscape function and able to supply information from the earliest times of rehabilitation up to the satisfaction of completion criteria, with a continuous record of ecological development. Moreover, it has been tested in a range of biomes ranging from desert to tropical rain forest, with useful information derived from the full range of landscape types.

\subsection{Uncertainties Posed by Terminology}

Objectives and closure criteria often include the terms "stability", "self-sustainability" and "resilience". Much of the early ecological literature that originally proposed these terms used metaphors to illustrate the concepts. For example, the "rolling ball" (Forman and Godron, 1987) and "basins of attraction" (Holling, 1973), which although introducing and illuminating the new principles they were advocating, do not provide a procedure for measurement. In the real world, these ecosystem properties appear to be ascribed or confirmed in retrospect rather than predicted ahead of time. Whilst of these terms and concepts resonate with stakeholders and have a high degree of acceptance in principle, they are conceptually complex notions, involving both strongly held ethical values as much as biophysical objectivity. The issue of "how much 
resilience or stability is enough?" therefore remains a question to be resolved in practice, and one that the approach described in this paper sets out to achieve in the context of monitoring rehabilitation progress.

\section{THE INFORMING SCIENCE}

\subsection{Landscape Ecology}

The term "landscape ecology" was introduced by Troll (1939), based on an appreciation of the work of Tansley (1935) and anticipated the synthesis of the broad spatial approach of geographers and the functional approach by ecologists (Naveh and Lieberman 1984; Forman and Godron, 1986). A landscape is "an area that is spatially heterogeneous in at least one factor of interest" (Turner et al., 2001), but stated in this form, the definition does not explicitly involve the dynamics of landscapes over time. Without this capacity, concepts such as landscape resilience in response to stress and disturbance cannot be usefully discussed. In natural, minimally disturbed landscapes much information is contained in the expression of biological and physical heterogeneity, rather than in the "mean value" of some spatially distributed attribute (Holling et al., 1996; Tongway and Ludwig 1990; Ludwig and Tongway, 1994). This is a marked departure from agronomic mindsets and practices, where deliberate homogenisation of landscapes is typical of the management of agricultural landscapes in order to achieve production objectives such as maximum or optimum yield per hectare. There are issues of the scale at which heterogeneity is expressed and gaining an appreciation of the importance of the scale at which surface processes are played out. Heterogeneity may be expressed in landscapes in terms of "patches" which are richer in resources such as water, nutrients, organic matte, due to accretion through time. These patches may be caused by the presence of flats or local depressions where water and other resources accumulate; by long-lived plants which concentrate nutrients and create more porous soils by root growth and litter decomposition (Tongway and Ludwig, 1990) and the activities of fauna whose burrowing activities enhance soil properties (Tongway et al., 1989; Whitford and Kay, 1999). Soil fauna also play a vital but as yet poorly appreciated role in landscape function (Lavelle, 1997).

\subsection{Landscape Function}

Recognition of pattern in landscapes has a long history, mainly focused on vascular plant pattern (review by Turner et al., 2001) but associating patterns in landscape with the set of processes that maintain it is a more recent development. This latter activity is more related to the questions: "how does this landscape work as a biophysical system? What goes wrong when stress or disturbance impacts the landscape? How can a "damaged landscape be repaired?" Landscape function as it has emerged over the past 20 years involves understanding (i) the spatial relationships among landscape elements, (ii) the flows of energy, minerals and water between the landscape elements and (iii) the dynamics of the landscape elements over time. This synthesis has enabled the concept of landscape function within landscape ecology to be developed, using information derived from a range of disciplines and exercised at a range of scales (Levin, 1992). Beyond the mere discrimination of patterns in space are the underlying causes of pattern, and what they mean in terms of understanding landscape function. It is the explicit linking of spatial pattern with the processes maintaining it that is the crux of the assessment of landscape function. This construct concentrates more on the role of biota in providing goods and services to their ecosystem in space and time and defocuses species identity as such, which are well dealt with by existing species-based procedures. Addressing landscape function includes the integration of processes mediated by both biotic and abiotic influences.

Tongway and Ludwig (1990) showed how landscape pattern elements in a 3-phase mosaic had highly discriminated soil chemical, physical and biological properties, the study of which facilitated the development of a conceptual framework expressing how the pattern was maintained by a range of biotic and abiotic surface processes acting across space, over time. The vegetation in each pattern element was strongly implicated in the on-going functioning of the landscape, but geomorphic processes of runoff, erosion and deposition were also involved. Ludwig and Tongway (1995) restated landscape function as the manner in which scarce, vital resources are retained, used and lost from landscapes. The application of these principles to a range of landscape types enabled Ludwig and Tongway (1997) to crystallise this paradigm shift in a conceptual framework (Figure 1) by which the functional status of a range of landscape types could be assessed by looking at the "economy of vital resources". A landscape may be characterised as "highly functional" if it is organised so that vital resources tend to be retained and utilised within the hydrologic 
boundaries, and leaking slowly beyond them. A dysfunctional landscape is one where these resources tend to increased rates of leakage or "run-out". Such landscapes deliver greatly increased rates of flow and volumes of water and sediment (Cramer and Hobbs, 2002; Prosser, 2002).

Clearly, there is a conceptual continuum from highly functional to highly dysfunctional (Tongway and Ludwig, 1997) as a consequence of the response of a landscape to stress and/or disturbance. The focus of landscape function assessment according to these principles can now be on the processes affecting the availability of vital resources in space and time, which can be directly assessed, rather than on concepts such as resilience and sustainability, which cannot. In making this change, assessors are able to move from the identification and listing of the biota (often charismatic) in the landscape to the study of the dynamics of resource availability within landscapes.

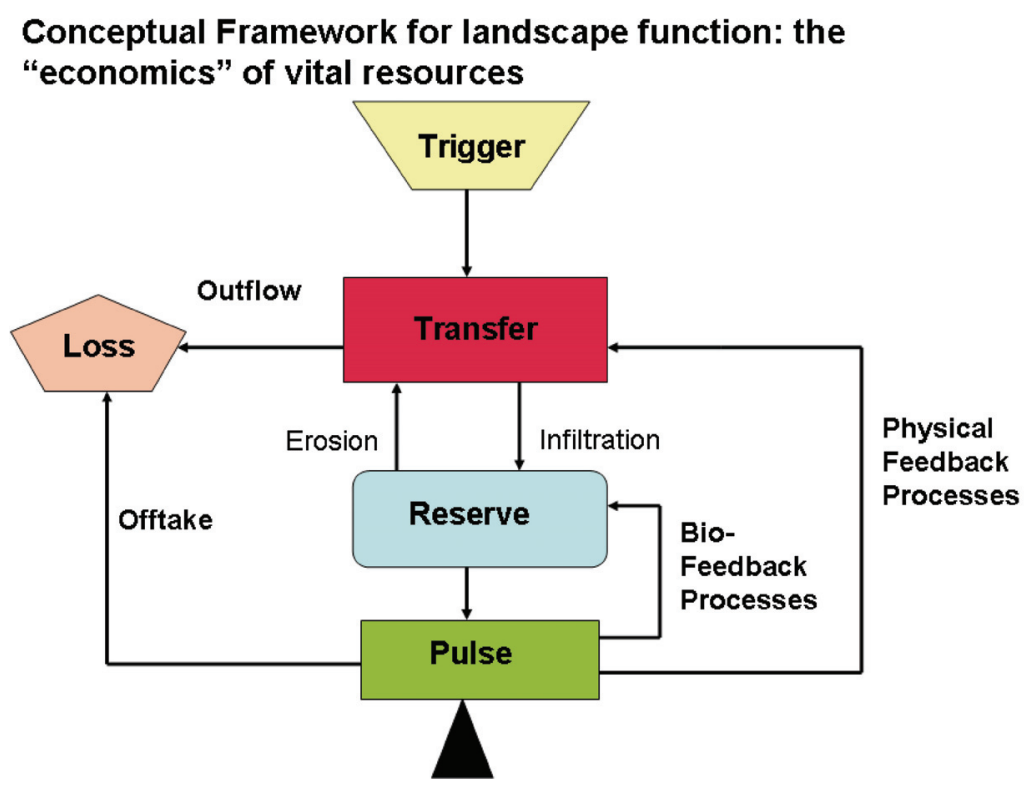

Figure 1 Conceptual Framework for landscape function: the economics of vital resources

This simple but highly inclusive framework (after Ludwig and Tongway, 1997) depicts landscape function as a sequence of processes, commencing with a trigger, such as rainfall which initiates transfer processes such as runoff and erosion that spatially relocates resources such as water, topsoil, organic matter and seeds across the landscape. Some of these resources may exit the landscape as outflow whilst some may be stored in the soil reserve. Some locations in the landscape absorb or capture more resources than other parts, due to differential runoff/runon characteristics. The reserve may be considered metaphorically as a "bank" dealing in many diverse but interacting "currencies"; water, nutrients, seeds and soil fauna. A pulse of plant growth and of mineralised nutrients may ensue, the magnitude of which depends on the status of the reserve. Some of the growth may be lost from the system by fire or herbivory as offtake, but much is cycled back to the reserve by a largely biological feedback where plant litter is reincorporated into the soil by a range of soil biota, and the seed pool is replenished. A physical feedback loop affects the extent to which changes in plant density at ground level regulate the amount and rate at which water and other resources are transported across the landscape. The framework (TTRP) is depicted here as being on a fulcrum, implying that there is a crucial balance between outflow/offtake and the two feedback loops which develop over time on rehabilitating mine sites. Typically, this balance is at its most sensitive in the early years of rehabilitation. A later section discusses this as a monitoring imperative in more detail.

In using this framework in monitoring, the emerging role of establishing vegetation in providing the crucial biological feedback can be explicitly recorded and commented on in terms of a "functional milestone" having been achieved. 
Since its original proposition, this framework has been tested in many other landscape types with a variety of land uses (Bastin et al., 2002; Ludwig et al., 2002; Ludwig et al., 2004; MacIntyre and Tongway 2005; Rezaei et al., 2006).

By adopting this mindset, the concept of landscape dysfunction was addressed in a way that enabled both the field assessment and the assignment of the degrees of dysfunction to be objectively addressed (Tongway and Ludwig 1997). Landscape function is a continuum between highly functional landscapes, characterised as "resource retentive" to highly dysfunctional where a large function in terms of resource availability in space and time, a range of field measures opened up as candidates for the monitoring and assessment.

\section{$4 \quad$ APPLICATION OF LANDSCAPE FUNCTION PRINCIPLES TO MONITORING PROCEDURES}

Because relative landscape function can be assessed by observing the processes affecting the fate of vital resources in space and time, a practical procedure was devised that focused on indicators of resource mobilisation, cross-country movement, depletion and concentration (Tongway and Smith 1989, Ludwig and Tongway 1993, Tongway and Hindley 2004). This procedure is called "Landscape Function Analysis" (LFA). The procedure is comprised of three sections: a conceptual framework, a field methodology and a data analysis module. The conceptual framework is the TTRP described above, which acts to make sure that all relevant processes are considered in the analysis. The field procedure collects data at two related scales. At the coarser scale, resource accumulating zones ("patches") and zones where resources tend to be shed ("interpatches") are identified and measured. This is done on a gradient-oriented transect or gradsect (Gillison and Brewer 1985), and recorded as a spatial listing or map of patches and interpatches. The appropriate scale or size of patches/interpatches is determined by looking at the scale at which resources are regulated on reference sites. The scale may range from centimetres (grasslands) to the tens of metres (banded woodlands). The typical or characteristic scale within a given landscape type may change with the degree of dysfunction, due to stress and/or disturbance.

Patches are characterised by clear evidence of resource retention or capture, such as the presence of fine sediment or plant litter, whereas interpatches should have few signs, if any, of resource accumulation. The size and orientation of patches is of specific interest, as monitoring over time and in response to seasonal conditions or a rare event can markedly change the organisation of the landscape. Fire, for example, can disrupt well-functioning landscapes. This initial analysis gives rise to a series of parameters describing the scale and effectiveness of resource re-allocation across the hillslope. More than one patch or interpatch type may be encountered, depending on the combination of biotic and abiotic features in the landscape.

At a second, finer scale, 1-m or less, each patch and interpatch type is assessed for the status of a number of surface processes using 11 focused indicators, derived from the literature. Each indicator addresses a process identifiable in the TTRP framework. Typically, observers assign the soil surface process to one of four or five classes, using written criteria and assisted by photo-standards provided in a manual. These indicators as a body, reflect the "quality" of the patches and interpatches in terms of their productive potential or soil "health". An Excel ${ }^{\mathrm{TM}}$ spreadsheet uses different combinations of indicators to derive three emergent soil surface properties reflecting stability to erosion, infiltration/runoff character and nutrient cycling status. The data are expressed as percentage values of the maximum possible score.

The indicators examine the status of a mix of biological and physical processes, so that during the progress of rehabilitation, the increasing role of the emerging vegetation in engaging in ecosystem processes will be recorded. Initially, biological indicators will be absent or at low levels of activity, but may progress markedly over time. For example, if leaf litter eventually accumulates and begins to decompose under the influence of fungi and soil biota, an additional effect is to improve soil aggregate stability; a kind of synergism. LFA addresses both processes explicitly. On the other hand, if engineered structures are failing by accelerated erosion, they will permit vital resources to flow rapidly out of the landscape, and the physical indicator values will assess the rate of resource regulation loss. In the early years of rehabilitation, it is important to find out if the rate of increase in biological processes is in excess of the decline in the capacity of engineered structures: if this is so, a case for self-sustainability begins to emerge. If the biota fail to "take control" of surface processes, the rehabilitation is likely to fail at some stage. Fig. 2 provides a conceptual framework for taking account of biotic and abiotic factors. 


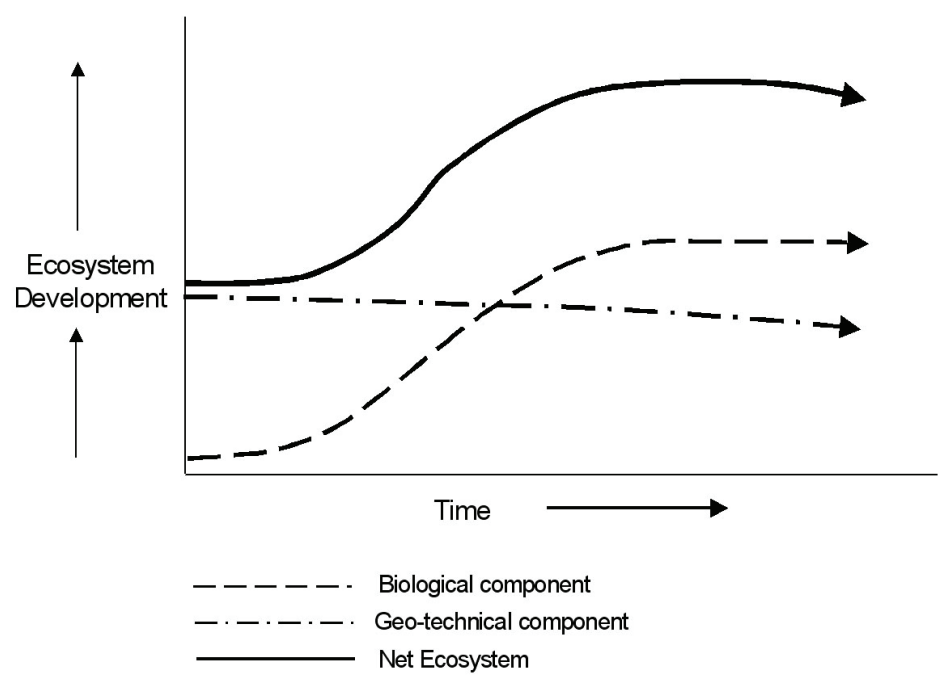

\section{Figure 2 Ecosystem response resolved into physical/engineered and biological components}

Landscape function indicators can be used to reflect "whole system" or "abiotic" or "biotic" properties. In this conceptual example, engineered structures and materials quality combine to produce an abiotic system that declines slowly over time, permitting the biological components to satisfactorily develop over time, so that the net landscape outcome is very satisfactory. The interpretational framework can deal with any outcome because of the breadth of scope of the contributing indicators

\section{DO LFA INDICES REFLECT MEASURED LANDSCAPE PROPERTIES?}

To have credibility, any monitoring system using indicators needs to be able to demonstrate that the data from the monitoring properly reflects the scientific properties ascribed to them. Many monitoring systems rely on inferences in a very general sense, rather than on established relationships. For example, the "focal species" approach (Lambeck, 1997) assumes or asserts that if a given (focal) species is not under threat, then all other species are also not under threat. A recent study has shown that the LFA indices have good relationships with measured properties (Tongway and Hindley 2003) across a range of mine types and rangelands in contrasting landscape types varying from sandy deserts to tropical rain forest. The nature of the relationship changes with biome (intercepts and gradients), but because LFA assessment is based on biophysical processes, the procedure has very broad potential application. Fig. 3 illustrates relationships for each of the LFA indices. We emphasize that LFA indices are intended for use across the full function/dysfunction spectrum, and were never intended to make subtle distinctions between very similar sites on a "once-only" basis. LFA data are intended for time series analysis to detect and quantify trend (see below). 

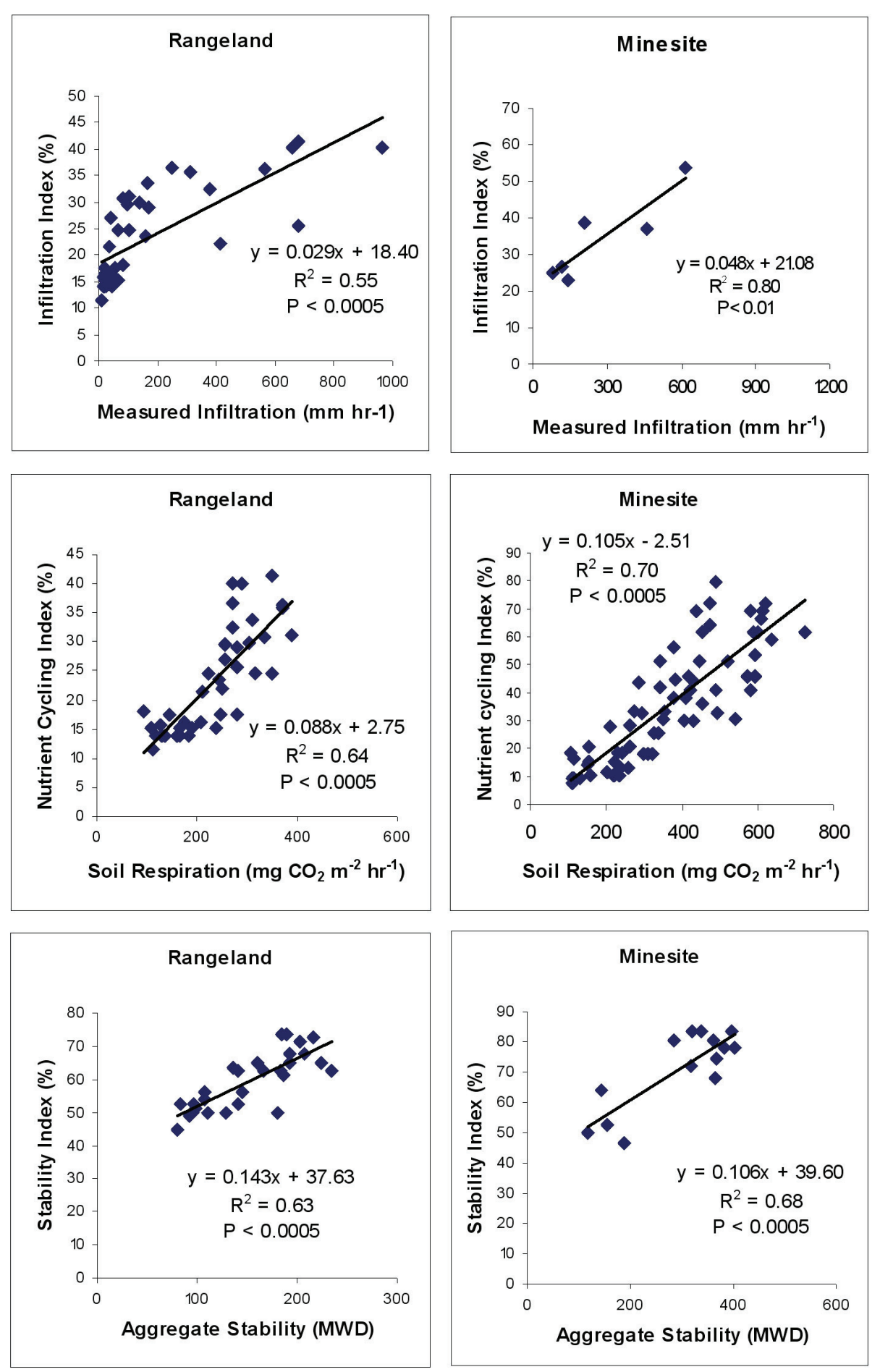

Figure 3 Relationships between LFA indices and measured landscape properties for rangeland and mined lands. Note: $A$. that the data include the reference sites, implying that the data across the rehabilitation and reference sites for a "coherent cloud" of data. B. The verification exercise involved as full a range of landscape function as possible 


\section{MAKING USE OF LANDSCAPE FUNCTION DATA FOR MINE CLOSURE}

In practice, LFA values from sites being assessed are compared to data from reference sites selected to represent an agreed and/or undisturbed landscape. Typically, one would expect young rehabilitation sites to have low to medium function, and that as vegetation establishes, to observe appropriately selected vegetation and other biota to contribute to landscape function, so that at some point, self sustainability would be achieved. This status would be characterised by low net erosion, moderate water use efficiency and enhanced, rising levels of nutrient cycling. On the other hand, an inappropriate species selection would be revealed particularly by the nutrient cycling index failing to increase. LFA provides an interpretational framework that examines the rate of progress of these indicators of landscape function. Fig. 4 shows the form of the interpretational framework, which embodies information about landscape function at the beginning of rehabilitation, an assessment of ultimate values obtained from the reference sites which represent the "biogeochemical potential" of the landscape type. This "S" shaped curve lends itself to the inference of selfsustainability (Tongway and Ludwig 2002, Tongway and Hindley 2004).

\section{Interpretational Framework}

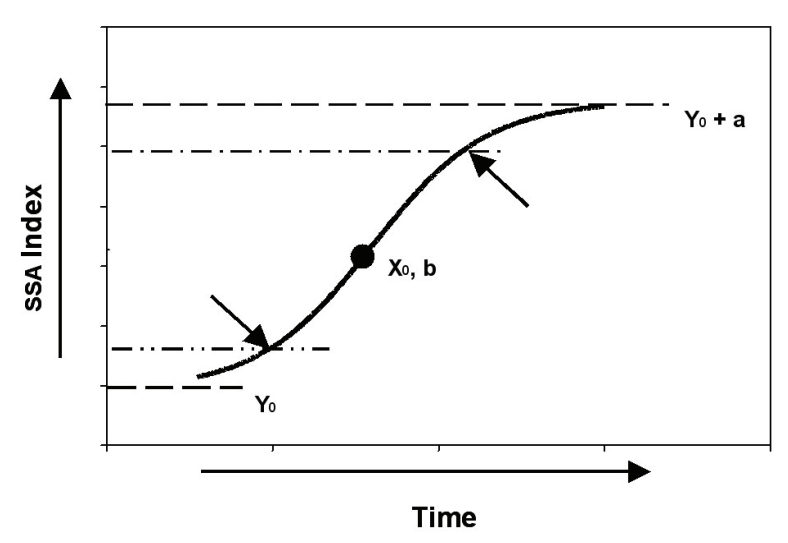

Figure 4 Depicts a fitted sigmoidal relationship of the form $y=$ yo $+a / 1+e-(x-x o) / b$

y represents an indicator of landscape function.

$\left(\mathbf{y}_{\mathbf{0}}+\mathbf{a}\right)$ represents the value of the upper asymptote, the biogeochemical site potential, limited by climate and parent material.

$\mathbf{y}_{\mathbf{0}}$ the computed value of the lower asymptote, the initial functional state at the beginning of rehabilitation.

$\mathbf{x}_{\mathbf{0}} \quad$ represents the location of the inflection point of the curve on the x-axis.

b the gradient, representing the rate of increase of the assessed index over time. 


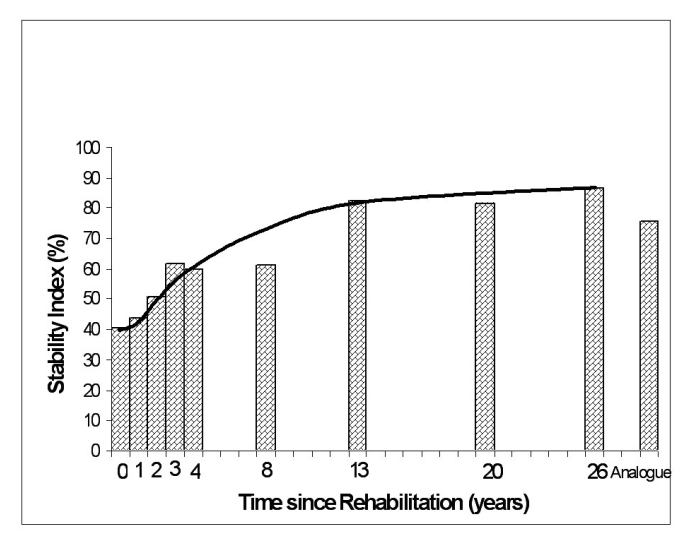

Figure 5 A sigmoidal or logistic curve fitted to a 26-year record of rehabilitation

LFA data can assist in defining the edaphic habitat for plants of particular interest. Walker and Langridge (1997) proposed the concept of the "plant available moisture" (PAM) vs "plant available nutrients" (PAN) as $\mathrm{x}$ and $\mathrm{y}$ coordinates representing the environmental niche of specified plants, a means of better understanding landscape degradation and rehabilitation progress. In practice, The LFA infiltration index and the nutrient cycling index could be used to "locate" the rehabilitation site on the PAN/PAM plan and compare this with the reference sites, where data would be amalgamated on a regional basis.

\section{CONCLUSION}

The concepts of landscape function and the procedures described for data collection and interpretation for the purpose of contributing to mine site closure provide additional, different information to existing monitoring tools and consideration should be given to including it in the toolbox of procedures and used in parallel with them. The procedure itself does not alter with changes in landscape type across a very large rainfall gradient, so once the principles are understood and the procedure is mastered, broad application can ensue. Landscape function draws its indicators from a wide range of scientific disciplines and can provide a predictive understanding of ecosystem or landscape trajectory, and thus provide crucial information about trend and response to stress and disturbance. In particular, the physical reasons for failed rehabilitation would emerge from this analysis and provide a means for restitution.

\section{REFERENCES}

ANZMEC (2000) Strategic Framework for Mine closure. ANZMEC Secretariat, Canberra ACT.

Bastin, G.N., Ludwig, J.A., Eager, R.W., Chewings, V.H. and Liedloff, A.C. (2002) Indicators of landscape function: comparing patchiness metrics using remotely-sensed data from rangelands. Ecological Indicators 1, pp. 247-260.

Cramer, V.A. and Hobbs, R.J. (2002) Ecological consequences of altered hydrological regimes in fragmented ecosystems in southern Australia: impacts and possible management responses. Austral Ecol 27, pp. 546-564.

Environment Australia (2002) Overview of Best Practice Environmental Management in Mining. Commonwealth of Australia, Canberra.

Forman, R.T.T. and Godron, M. (1986) Landscape Ecology. John Wiley \& Sons, New York.

Gillison, A.N. and Brewer, K.R.W. (1985) The use of gradient directed transects or gradsects in natural resource survey. Journal of Environmental Management 20, pp. 103-27.

Holling, C.S. (1973) Resilience and Stability of ecological Systems. Annual Review of Ecology and Systematics. Annual Reviews Inc. Palo Alto, California, USA.

Holling, C.S., Peterson, G., Marples, P., Sendzmir, J., Redford, K., Gunderson, L. and Lambert, D. (1996) Selforganisation in ecosystems: lumpy geometries, periodicities and morphologies. In Global Change and terrestrial Ecosystems. Eds Brian Walker and Will Stephen, Cambridge University press, New York, USA.

Lambeck, R.J. (1997) Focal species: a multi-species umbrella for nature conservation. Conservation Biology 11, 859 p. 
Lavelle, P. (1997) Faunal Activities and Soil Processes: Adaptive Strategies That Determine Ecosystem Function. Advances in Ecological Research 27, pp. 93-132.

Levin, S.A. (1992) The problem of pattern and scale in Ecology. Ecology 73, pp. 1943-1983.

Ludwig, J.A. and Tongway, D.J. (1993) Monitoring the condition of Australian arid lands: linked plant-soil indicators. In Ecological Indicators. D.H. McKenzie, D.E. Hyatt and V.J. McDonald (eds), pp. 765-72. Elsevier Applied Science, New York, USA.

Ludwig, J.A. and Tongway, D.J. (1995) Spatial organisation of landscapes and its function in semi-arid woodlands, Australia. Landscape Ecology 10, pp. 51-63.

Ludwig, J.A. and Tongway, D.J. (1997) A Landscape Approach to Rangeland Ecology. In J.A. Ludwig, D.J. Tongway, D. Freudenberger, J. Noble and K. Hodgkinson (eds), Landscape ecology, Function and Management: Principles from Australia's Rangelands. CSIRO, Melbourne, Australia, pp. 1-12. (Now available gratis from david.tongway@iinet.net.au).

Ludwig, J.A., Eager, R.W., Bastin, G.N., Chewings, V.H. and Liedloff, A.C. (2004) A leakiness index for assessing landscape function using remote sensing. Landscape ecology 17, pp. 157-171.

Ludwig, J.A., Tongway, D.J., Bastin, G.N. and James, C.D. (2004) Monitoring ecological indicators of rangeland functional integrity in relation to biodiversity at local to regional scales. Austral Ecolology 29, pp. 108-120.

McIntyre, S. and Tongway, D. (2005) Grassland structure in native pastures: links to soil surface condition. Ecological Management and Restoration, 6, (1), April 2005, pp. 45-50.

Naveh, Z. and Lieberman, A.S. (1984) Landscape Ecology, Theory and Application. Springer Verlag, New York, USA.

Prosser, I.P., Moran, C.J. and Lu, H. (2002) Regional patterns of erosion and sediment transport in the Burdekin River Catchment, Final report. Meat \& Livestock Australia, Sydney, Australia.

Rezaei, S.A., Arzani, H. and Tongway, D. (2006) Assessing rangeland capability in Iran using landscape function indices based on soil surface attributes. J Arid Environ. 65, pp. 460-473.

Tansley, A.G. (1935) The use and abuse of vegetational concepts and terms. Ecology 16, pp. 284-307.

Tongway, D.J. and Hindley, N. (2003) Indicators of Ecosystem Rehabilitation Success Stage Two: verification of EFA Indicators. http://www.cse.csiro.au/research/efa/.

Tongway, D.J. and Hindley, N.L. (2004) Landscape Function Analysis: a system for monitoring rangeland function. African Journal of Range and Forest Science, 21, pp. 41-45.

Tongway, D.J. and Ludwig, J.A. (1990) Vegetation and soil patterning in semi-arid mulga lands of Eastern Australia. Australian Journal of Ecology 15, pp. 23-34.

Tongway, D.J. and Ludwig, J.A. (1997) The Nature of Landscape Dysfunction in Rangelands. In J.A. Ludwig, D.J. Tongway, D. Freudenberger, J. Noble and K. Hodgkinson (eds), Landscape Ecology, Function and Management: Principles from Australia's Rangelands. CSIRO, Melbourne, Australia, pp. 13-22. Now available, gratis, from dtongway@iinet.net.au.

Tongway, D.J. and Ludwig, J.A. (2002) Reversing Desertification in Rattan Lal (ed) Encyclopaedia of Soil Science. Marcel Dekker, New York.

Tongway, D.J. and Smith, E.L. (1989) Soil surface features as indicators of rangeland site productivity. Australian Rangeland Journal 11, pp. 15-20.

Tongway, D.J., Whitford, W.G. and Ludwig, J.A. (1989) Mulga log mounds: fertile patches in the semi-arid woodlands of eastern Australia. Aust. J. Ecol. 14, pp. 263-268.

Turner, M.G., Gardner, R.H. and O’Neill, R.V. (2001) Chapter 5, Quantifying Landscape pattern in Landscape Ecology in Theory and Practice Pattern and process. Springer Verlag, New York, USA.

UNDP (2005) Mining for Closure: Policies and Guidelines for sustainable mining practice and closure of mines. UNDP, UNEP, OSCE.

Walker, B.H. and Langridge, J.L. (1997) Predicting savanna vegetation structure on the basis of plant available moisture (PAM) and plant available nutrients (PAN): a case study from Australia. Journal of Biogeography 25, pp. 813-825.

Whitford, W.G. and Kay, F. (1999) Biopedturbation by mammals in deserts: a review J Arid Environ. 41, pp. 203-220. 